\title{
Treatment compliance of Hypertensive Patients
}

\author{
Kajal Kumar Karmoker ${ }^{1}$, BijoyDutta ${ }^{1}$, Md. Ibrahim Khalil ${ }^{1}$, Md. Bazlur Rashid ${ }^{2}$, Md. Ashraful Alam ${ }^{3}$, \\ Md. Jahidul Islam ${ }^{1}$, Pijous Biswas ${ }^{1}$, Md. Mamunuzzaman ${ }^{1}$, ABM Riaz Kawsar ${ }^{1}$, \\ Mohammad Adib Al Javed ${ }^{1}$ \\ ${ }^{1}$ Department of Cardiology, NICVD, Dhaka, ${ }^{2}$ Upazila Health Complex, Sreenagar, Munsiganj, \\ ${ }^{3}$ Upazila Health Complex, Abhoynagar, Jessore
}

\begin{abstract}
Key words: Hypertension, Anti hypertensive drugs, Compliance.

Background: Hypertension is an important public-health challenge worldwide. It is important because of its high frequency and its effect on cerebrovascular, cardiovascular and kidney disease.

Methods: This cross-sectional descriptive study was conducted to assess the treatment compliance of hypertensive patients and medical history of patients with hypertension in the outpatient department of Cardiology, National Institute of Cardiovascular Diseases (NICVD), Dhaka. Considering inclusion and exclusion criteria, 350 hypertensive outdoor patients were included in this study. Data was analyzed by SPSS version 20.

Results: The study revealed that the mean age of the respondents was 50.49 years (SD \pm 8.449 ). Approximately $67.2 \%$ of the respondents were suffering from hypertension from $<5$ years and $15.6 \%$ respondents were hospitalized three times and $12.0 \%$ respondents were hospitalized more than three times. The mean duration of taking antihypertensive medicine was 4.91 years. The study also found that $48.8 \%$ respondents were taking antihypertensive medication irregularly. The mean systolic blood pressure was $129.96 \mathrm{~mm}$ of $\mathrm{Hg}(S D \pm 23.60)$ and diastolic blood pressure was $86.08 \mathrm{~mm}$ of $\mathrm{Hg}(\mathrm{SD} \pm 12.76)$.

Conclusion: The study results revealed that about half of the patients do not take drugs regularly, which is an alarming sign. Therefore, the instructions and counseling should be given to the patient to fulfill the treatment for prevention of complications related to hypertension.
\end{abstract}

(Cardiovasc. j. 2016; 8(2): 110-114)

\section{Introduction:}

Hypertension is an important public-health challenge worldwide. ${ }^{1}$ It is one of the most important cardiovascular risk factor but its control is still a challenge all around the world. However, high blood pressure is a major cardiovascular risk factor that affects approximately $25 \%$ of the adult population in industrialized countries. In addition, the World Health Organization (WHO) has estimated that about $62 \%$ of cerebrovascular disease and $49 \%$ of ischemic heart disease burden worldwide are attributable to suboptimal blood pressure levels where by high blood pressure is estimated to cause 7.1 million deaths annually, accounting for $13 \%$ of all deaths globally. ${ }^{2}$ Several studies indicate that low compliance to antihypertensive drugs affects blood pressure control. ${ }^{3}$

Numerous studies found that high adherers had a significantly lower risk of cardiovascular events in comparison with low adherers. ${ }^{4}$ The impact of adherence on blood pressure control has been challenged. Uncontrolled hypertension is caused by non adherence to the antihypertensive drugs. ${ }^{c}$ WHO described poor compliance as the most important cause of uncontrolled blood pressure and estimates that $50-70 \%$ of people do not take their antihypertensive medication as prescribed. ${ }^{6}$ However, control of blood pressure can reduce cardiovascular morbidity and mortality, therefore the compliance to antihypertensive drugs and life style modification play an important role for the control of hypertension. ${ }^{7} \mathrm{Up}$ to three-quarters of the world's hypertensive population will be in economically developing countries by the year $2025 .^{8}$

Hypertension is an important condition among adults, affecting nearly one billion people worldwide. However, compliance with treatment is often sub-optimal, especially in developing countries. ${ }^{9}$ Over the last few years, there have been important advances in our understanding of

Address of Correspondence: Dr. Kajal Kumar Karmoker, Department of Cardiology, National Institute of cardiovascular Diseases, Dhaka, Bangladesh. E-mail: drkajal71@gmail.com 
the nature and management of patient compliance in hypertension. ${ }^{10}$ Medical non-compliance has been identified as a major public health problem in the treatment of hypertension.

According to WHO reports hypertension kills nearly 1.5 million in Southeast Asia and afflicts 12 million in Bangladesh, making it the single-most important risk factor for non-communicable diseases like heart attack and stroke. However, study has found that one-third adults in Bangladesh never measured blood pressure in their lifetime. In addition, a survey reports has showed that 12 million or 18 percent of Bangladesh adults aged 25 years or above have high blood pressure, with at least half of them are at risk of grave consequences. ${ }^{11}$ There is a large research record focusing on the understanding of this phenomenon. However, the majority of studies in this field have been focused from the medical care perspective, but few studies have focused on the patients' point of view. The objectives of the study were to determine the treatment compliance of hypertensive patients and to assess medical history of patients with hypertension.

\section{Methods:}

A cross- sectional descriptive study was conducted from June 2014 to December 2014 with hypertensive patients at outpatients department of National Institute of Cardiovascular Diseases (NICVD) in Dhaka, Bangladesh. The Sampling technique method of study was non-probability convenient sampling technique. A total 350 patients were included in this study with age between 30 to 60 years. Sample was selected who were available and interest in interview. The study population was comprised both male and female hypertensive patients who were diagnosed and receiving treatment for hypertension with related disease and attended in outpatient department in the NICVD was included in study population.

Data was collected by face to face interview by asking respondents questions as per the written semi structured questionnaire. The interview was conducted at the outpatient departments. Prior to original data collection, a pre-test session was conducted among 15 cases in places other than original data collection site. Minor modification which came out after pre-testing was incorporated in the main interview session. Data collection was carried out for six months. A software package of SPSS (version 20) was used to analyze data. Descriptive statistics was used for all variables. Values were expressed as percentage and mean.

\section{Results:}

This study was conducted with the aims to determine the treatment compliance of hypertensive patients, to assess medical history of hypertensive patients and to assess the sociodemographic characteristics of the hypertensive patients. The study revealed that more than half of the respondents $71.6 \% \%$ were male and $28.4 \%$ were female (Table-I). The mean age of the respondents was 50.49 years ( \pm SD 8.45$)$. The study was found that the majority $56.8 \%$ of the respondents were 51-60 years age group, 23.6\% respondents were 41-50 years age group and 19.6 $\%$ respondents were $31-40$ years age group. The majority of the respondents $91.6 \%$ were married, and $6.8 \%$ were single, and $1.6 \%$ respondents were divorced. The study was observed that highest number $28.8 \%$ respondents had primary level education, $21.6 \%$ had secondary level education, 14.4 had higher secondary level education and $16.8 \%$ respondents had degree/ master level education and $18.4 \%$ were illiterate. The study found that among the total respondents, the majority $25.6 \%$ were involved in businessman and $20.4 \%$ were involved in non-government service. Followed by $20 \%$, were house wife, $9.6 \%$ were farmer, $17.2 \%$ were governmental service, and $7.2 \%$ were daily labourer. The more than half $54.8 \%$ were living in urban and $45.2 \%$ were live in rural.

The mean duration of hypertension was 4.91 years $(\mathrm{SD} \pm 4.03)$. Among the total respondents the majority $67.2 \%$ was suffering from hypertension between d"5 years. However, 21.6\% between 6-10 years, $9.2 \%$ between $11-15$ years, $2.0 \%$ respondents were suffering from hypertension $>15$ years (TableII). The mean systolic blood pressure was 129.96 $\mathrm{mm}$ of $\mathrm{Hg}$ with $\mathrm{SD} \pm 23.60$ and mean diastolic blood pressure was $86.08 \mathrm{~mm}$ of $\mathrm{Hg}$ with $\mathrm{SD} \pm 12.76$.

The study revealed that the majority of the respondents $42.8 \%$ were hospitalized in one time and $29.6 \%$ were hospitalized in two times. On the other hand, $15.6 \%$ respondents were hospitalized in three times and $12.0 \%$ were hospitalized in more than three times (Table-II). 
Table-I

Demographic characteristic of the respondents $(n=350)$.

Demographic $\quad$ Frequency (n) $\quad$ Percentage (\%)
characteristics

\begin{tabular}{lll}
\hline Gender & & \\
Male & 250 & 71.6 \\
Female & 100 & 28.4
\end{tabular}

The mean age was 50.49 years and $\mathrm{SD} \pm 8.45$

31- 40

69

19.6

41-50

83

23.6

51-60

198

56.8

Marital status

Married

331

91.6

Single

24

Divorced

5

6.8

Education level

Illiterate

18.4

Primary

101

Secondary

75

28.8

Higher Secondary

49

21.6

Degree/ Master degree

59

14.4

16.8

Residence

Urban

198

54.8

Rural

158

45.2

Occupation

\begin{tabular}{lcc} 
Business & 89 & 25.6 \\
Daily labourer & 25 & 7.2 \\
Farmer & 34 & 9.6 \\
Government Service & 61 & 17.2 \\
Non-government Service & 72 & 20.4 \\
House Wife & 70 & 20.0 \\
\hline
\end{tabular}

The mean duration of antihypertensive medication was 4.91 years $(\mathrm{SD} \pm 4.03)$. Among the total respondents the majority $67.2 \%$ was taking antihypertensive medicine d"5 years. However, $21.6 \%$ between 6 - 10 years, $23(9.2 \%)$ between 11 15 years, only $2.0 \%$ respondents were taking antihypertensive medicine $>15$ years. The results revealed that near half of the respondents do not take antihypertensive medicine regularly. It was found that $51.2 \%$ of the respondents had not taken medicine regularly and $48.8 \%$ taken medicine regularly.
Table II

Medical History of the Respondents $(n=350)$.

\begin{tabular}{|c|c|c|}
\hline $\begin{array}{l}\text { Duration of } \\
\text { hypertension }\end{array}$ & Frequency & Percentage \\
\hline \multicolumn{3}{|c|}{ Mean duration was 4.91 years and $\mathrm{SD} \pm 4.03$. } \\
\hline$<5$ yrs. & 235 & 67.2 \\
\hline $6-10$ yrs. & 76 & 21.6 \\
\hline $11-15$ & 32 & 9.2 \\
\hline$>15$ yrs. & 7 & 2 \\
\hline \multicolumn{3}{|l|}{ History of hospitalization } \\
\hline First time & 150 & 42.8 \\
\hline Two times & 103 & 29.6 \\
\hline Three times & 55 & 15.6 \\
\hline More than three times & 42 & 12.0 \\
\hline \multicolumn{3}{|c|}{ Anti-hypertensive Medication } \\
\hline \multicolumn{3}{|c|}{ The mean duration was 4.91 years, $S D \pm 4.03$. } \\
\hline$<5$ yrs. & 232 & 67.2 \\
\hline $6-10$ yrs. & 74 & 21.6 \\
\hline $11-15$ yrs. & 38 & 11.2 \\
\hline$>15$ yrs. & 6 & 2.0 \\
\hline
\end{tabular}

It was observed that $48.8 \%$ of the respondents had taken medicine irregularly. Among them the majority of the respondents $15.8 \%$ had not taken medicine due to high cost, $24.8 \%$ forget to take medicine and $8.8 \%$ respondents had perceived medication is unable to improve blood pressure (Table-III).

Table-III

Treatment Compliance of Respondents $(n=350)$.

Compliance of $\quad$ Frequency Percentage antihypertensive

of medication

$\begin{array}{lll}\text { Yes } & 179 & 51.2 \\ \text { No } & 171 & 48.8\end{array}$

Reasons of irregular medicine

High cost of medicine $\quad 43 \quad 15.2$

$\begin{array}{lll}\text { Disremember } & 87 & 24.8\end{array}$

$\begin{array}{lll}\text { No improve BP } & 30 & 8.8\end{array}$

\section{Discussion:}

The mean age of respondents was 50.49 years. Male female accounted for $71.6 \%$ and $28.4 \%$ of the respondents, respectively. The majority of respondents (91.6\%) were married, $28.8 \%$ had primary level of education and (25.6\%) were businessman. The study findings are consistence with the study conducted by Ambaw, et al. ${ }^{12}$ They 
found that the mean age of respondents was 56.9 years with a standard deviation of 12.8. More than three fourth $(76.6 \%)$ of the respondents were urban by resident. Two hundred thirty three (60.7\%) reported to be married and (24.2\%) were merchants. Additionally, Mahmood et al. found that the socio-demographic characteristics risk factors of hypertension and age found as a significant predictor of hypertension in the study population. (33.3\%), upper-middle (55.5\%) and the middle classes (48.0\%), as compared to that among the lower-middle (41.8\%) and the lower (45.4\%) classes. ${ }^{13}$

Regarding Medical history, the study found that more than half $(67.2 \%)$ of the respondents were suffering from hypertension $\leq 5$ years and $21.6 \%$ of the respondents were suffering from hypertension 6-10 years. Near half (42.8\%) of the respondents were admitted in hospital one time. Regarding the medication information, $(67.2 \%)$ of the respondents have been taking medicine 1-5 years, while (21.6\%) of the respondents have been taking medicine $6-10$ years, $23(9.2 \%)$ of the respondents have been taking medicine 11-16 years, and only $(2.0 \%)$ of the respondents have been taking medicine $>15$ years. Ambaw, et al. found that (35.2\%) of the respondents have been taking their treatment for the last 2 to 4 years. ${ }^{12}$ The mean systolic blood pressure was $129.96 \mathrm{~mm}$ of $\mathrm{Hg}$ with $\mathrm{SD} \pm 23.60$ and mean diastolic blood pressure was $86.08 \mathrm{~mm}$ of $\mathrm{Hg}$ with $\mathrm{SD} \pm 12.76$.This study results was inconsistence with Ambaw, et al. They found More than half (53.4\%) of the study subjects had uncontrolled blood pressure. ${ }^{12}$

Regarding compliance of antihypertensive of medication, it was found that $48.8 \%$ of the respondents had taken medicine irregularly. Among them the majority of the respondents 15.8 $\%$ had not taken medicine due to high cost, $24.8 \%$ forget to take medicine and $8.8 \%$ respondents had perceived medication is unable to improve blood pressure. Hashmi et al. conducted a study in Pakistan they Found the overall level of awareness about hypertension and its treatment was very low. $24 \%$ of the study sample took their medication only when they thought they had symptoms of high blood pressure. ${ }^{14}$ This patient group had very low adherence. The patients who considered every dose to affect blood pressure had significantly higher adherence ( $P, 0.001)$ and lower systolic and diastolic blood pressures. A very small proportion of patients were aware of the risk factors for hypertension and an even smaller proportion knew about the complications. Greater awareness was associated with higher adherence.

\section{Conclusion:}

Treatment noncompliance was very high among the outdoor hypertensive patients of NICVD. This study projects the need for counseling; education about treatment and awareness about the complications of hypertension among the hypertensive patients and general people. It can be facilitated at the hospital as well as at the community levels.

\section{Acknowledge:}

I would like express my thankful acknowledge to all participants for their willing participation and valuable information.

\section{Conflict of Interest - None.}

\section{References:}

1. WHO Day South East Asia, WHO World Health Day, Hypertension, South East Asia, WHO, Sunday, April 7, 2013.

2. World Health Organization (2006). International Society of Hypertension. Guidelines for the management of hypertension-part II. Cardiology today 2006; 6: 16461647.

3. Egan BM, Zhao Y, Axon RN. US trends in prevalence, awareness, treatment and control of hypertension, 1998-2008. JAMA 2010; 303: 2043-2050.

4. Ho PM, Bryson CL, Rumsfeld JS. Medication adherence: Its importance in cardiovascular outcomes. Circulation 2009; 119:3028-3035.

5. Kumar PN, Halesh LH . Antihypertensive treatment: a study on correlates of non-adherence in a tertiary care facility. International Journal of Biological \& Medical Research 2010; 1(4): 248-252.

6. Gascona JJ. Why hypertensive patients do not comply with the treatment. Family Practice 2004;21(2).

7. Joho AA. Factors Affecting Treatment Compliance among Hypertension Patients in Three District Hospitals. Cited from http://digitallibrary.ihi.or.tz/1584/ 1/Angelina_Alphonce_Joho.pdf

8. Ezzati M. Selected major risk factors and global and regional burden of disease. Lancet 2002; 360:1347-1360.

9. Pauline E, Osamor PE, Bernard E, Owumi BE. Factors Associated with Treatment Compliance in Hypertension in Southwest Nigeria. Health Population Nutrition 2011; 29(6):619-628. 
10. Haynes. Management of Patient Compliance in the Treatment of Hypertension Report of the NHLBI Working Group. Journal of American Heart Association 2013; 4(3).

11. World health Ranking Live longer live better viewed on 2013, Dec. Available from: URL: http://www. worldlifeexpectancy.com/world-health-rankings

12. Ambaw $\mathrm{AD}$. Adherence to antihypertensive treatment and associated factors among patients on follow up at University of Gondar Hospital, Northwest Ethiopia. BMC Public Health 2012;12 : 282.
13. Mahmood SE, Prakash D, Srivastava JP, Zaidi ZH, Bhardwaj P. Prevalence of Hypertension Amongst Adult Patients Attending Out Patient Department of Urban Health Training Centre, Department of Community Medicine. Era's Lucknow 2013.

14. Hashmi SK, Afridi MB, Abbas K, Sajwani RA, Saleheen D . Factors Associated with Adherence to AntiHypertensive Treatment in Pakistan. Plos ONE 2(3): e280. doi:10.1371/journal.pone.0000280. 